\title{
Los estudiantes de las Escuelas Normales Rurales en el conflicto internacional de la guerra fría*
}

\author{
Rural Teacher-Training College Students \\ During the International Cold War Conflict
}

\author{
Mónica Naymich López Macedonio \\ (D) https://orcid.org/0000-0001-9157-3741 \\ Instituto de Investigaciones Sociales \\ Universidad Nacional Autónoma de México, México \\ utopistica@gmail.com
}

Resumen: En este artículo nos proponemos develar algunos de los hallazgos de una investigación más amplia acerca de la Federación de Estudiantes Campesinos Socialistas de México (FECSM) que fue sustentada, principalmente, en el archivo de la Dirección Federal de Seguridad, en donde se esclarece el posicionamiento político e ideológico que los estudiantes normalistas rurales, organizados en la FECSM, mostraron ante el conflicto internacional de la guerra fría, y se explica el nacimiento de esta organización como resultado de las alianzas políticas fraguadas en vísperas y durante la segunda guerra mundial, concretamente, entre los representantes de la Internacional Comunista en México y el gobierno de Lázaro Cárdenas, que dieron como resultado la

* El presente artículo fue realizado en el marco de la estancia de investigación posdoctoral en el Instituto de Investigaciones Sociales (IIs) en calidad de miembro del Programa Becas Posdoctorales de la UNAM, que es promovido y financiado por la Coordinación de Humanidades.

cómo citAR: López Macedonio, M. N. (2020). Los estudiantes de las escuelas normales rurales en el conflicto internacional de la guerra fría. Secuencia (108), e1723. Dor: https://doi.org/10.18234/secuencia. v0i108.1723

c) 98

Esta obra está protegida bajo una Licencia Creative Commons Atribución-NoComercial 4.0 Internacional. 
estructura corporativa que después conocimos y con la que se gobernó este país durante gran parte del siglo Xx. La FECSM fue una organización estudiantil emblemática del nacionalismo revolucionario que estuvo adscrita a organizaciones estudiantiles internacionales abiertamente identificadas con el antimperialismo de la Unión Soviética.

Palabras clave: Federación de Estudiantes Campesinos Socialistas de México; Confederación de Jóvenes Mexicanos; Unión Internacional de Estudiantes; Federación Mundial de la Juventud Democrática; guerra fría.

Abstract: This article shares some of the findings of a broader research project on the Federation of Socialist Peasant Students of Mexico (fECSM) based mainly on the Federal Security Directorate archives. It clarifies the political and ideological position of rural trainee teachers, organized in the FECSM, on the international cold war conflict. It explains the origin of this organization as a result of the political alliances forged on the eve of and during the second world war, specifically between representatives of the Communist International in Mexico and the Lázaro Cárdenas government, which resulted in the corporate structure that subsequently governed this country for much of the 20th century. The FECSM was an emblematic revolutionary nationalist student organization, attached to international student organizations that openly identified with the anti-imperialism of the Soviet Union.

Keywords: Federation of Socialist Peasant Students of Mexico; Mexican Youth Confederation; International Union of Students; World Federation of Democratic Youth; cold war.

Recibido: 28 de febrero de 2019 Aceptado: 17 de septiembre de 2019 Publicado: 21 de agosto de 2020

$\mathrm{L}$ os estudiantes de las Escuelas Normales Rurales también se posicionaron en el conflicto internacional de la guerra fría. Ni la historiografía de dicho conflicto ni la de las Escuelas Normales Rurales habían sugerido la posibilidad de tal conexión; pero la hubo. En una época en la que, en México, el corporativismo funcionaba como sistema de gobierno, tal posicionamiento lo 
hicieron como miembros de un organismo estudiantil que los representaba y que necesariamente estaba adscrito al andamiaje corporativo del Estado posrevolucionario. A partir de algunas evidencias documentales, localizadas en los desclasificados del Centro de Investigación y Seguridad Nacional (CISEN), concretamente, el archivo de la Dirección Federal de Seguridad (DFS), ha sido posible develar esa conexión que, advierto, es sólo la punta del iceberg que esperamos aliente futuras investigaciones. Algunas pistas que nos ayudan a documentar el nacimiento de la organización estudiantil de las Escuelas Normales Rurales han sido localizadas en el Archivo Histórico de la Secretaría de Educación Pública (AHSEP), las cuales han sido incorporadas en este texto. Breves fragmentos de entrevistas realizadas a exdirigentes estudiantiles de las Normales Rurales también fueron incluidos, las cuales nos dan pistas para documentar el quehacer y los alcances de la organización estudiantil.

Para conocer el posicionamiento de los estudiantes de las Escuelas Normales Rurales en el conflicto internacional de la guerra fría es indispensable identificar la existencia de la Federación de Estudiantes Campesinos Socialistas de México FECSM, organismo estudiantil en el que militaron y que los representó, entre 1935 y 1969, como un corporativo nacional ante las autoridades de la Secretaría de Educación Pública (SEP). Es importante señalar que pocos trabajos han documentado la historia de la FECSM. Breves referencias han sido enunciadas en La escuela como opción de vida. La formación de maestros normalistas rurales en México, 1921-1945 (Civera, 2008), y en el artículo “¡Por qué somos estudiantes de segunda: la organización de los estudiantes campesinos en México 1932-1941!", en el que, apoyada en documentos oficiales resguardados en el Archivo Histórico de la Secretaría de Educación Pública (AHSEP) -expedientes de alumnos, informes de directores e inspectores, comunicados de los estudiantes y padres de familia a las autoridades educativas-, Alicia Civera ha descrito la participación de los estudiantes normalistas rurales en la creación del autogobierno, entorno en el que se conformó una cultura estudiantil particular, es decir, la de considerarse "estudiantes de segunda" (Civera, 2011). Otras menciones que aluden a la fundación de la FECSM, también sustentadas en documentación de la SEP, han sido expuestas en los trabajos de Maximino Ortiz Jiménez (1991), La formación de maestros rurales en el Estado de México, 19271940, y de Manuela Sepúlveda (1976), La política educativa y las escuelas rurales en la década de los treinta. El caso de las Escuelas Regionales Campesinas en 1936. Sergio Ortiz Briano (2012), en su libro Entre la nostalgia y la incertidumbre. Movimiento estudiantil en el normalismo rural mexicano, ofrece continuas referencias 
de la FECSM, pero no es el tema central de su investigación. Hasta ahora sólo existe una investigación académica que se ha puesto como reto la escritura de una historia en la que la FECSM es la protagonista. Se trata de la tesis doctoral "Historia de una relación institucional: los estudiantes normalistas rurales organizados en la Federación de Estudiantes Campesinos Socialistas de México y el Estado mexicano del siglo xx (1935-1969)" (López Macedonio, 2016); defendida en El Colegio de México y reconocida, bajo concurso, por la Sociedad Mexicana de Historia de la Educación, A. C. (Somehide) como la mejor tesis de doctorado en el marco de su XV Encuentro Internacional de Historia de la Educación: Movimientos, Desigualdades y Reformas Educativas en el Tiempo, que fue llevado a cabo en Pachuca, Hidalgo, en noviembre de 2018. El presente artículo refiere algunos de los hallazgos de ese trabajo, pero también, de las labores de investigación que actualmente son realizadas en el Instituto de Investigaciones Sociales, en el marco del Programa Becas Posdoctorales en la unAM y que es patrocinado por la Coordinación de Humanidades.

De acuerdo con la documentación que ha sido consultada y que aporta evidencias para reconstruir el posicionamiento de los estudiantes normalistas rurales organizados en la FECSM en el conflicto internacional de la guerra fría, podemos sugerir que ese organismo estudiantil fue sólo un actor más que era incluido en la delegación que representaba a México en los congresos de estudiantes a los que convocaron organismos de corte internacional que estuvieron alineados al bloque que lideraba la Unión Soviética. Se observa el protagonismo, en cambio, de la Confederación de Jóvenes Mexicanos (CJM), central estudiantil en la que, desde los tiempos del gobierno de Lázaro Cárdenas, estuvieron unificadas las organizaciones estudiantiles de las universidades públicas. La FECSM representaba a las Escuelas Normales Rurales, las cuales habían defendido el proyecto educativo oficial que estableció la educación socialista. La CJM fue el organismo estudiantil que convocó y organizó de manera recurrente a la delegación estudiantil que representó a México en los congresos a los que convocaron organismos internacionales alineados a la esfera soviética. Sin embargo, aunque la participación de la FECSM como organización no fue protagónica, debe considerarse que, al finalizar la década de los cincuenta, la CJM fue dirigida por exsecretarios generales de la FECSM $y$, por consiguiente, la vida de las dos organizaciones de estudiantes estuvo intrínsecamente relacionada (López Macedonio, 2016, pp. 60-61).

En la vida nacional, la FECSM fue importante en la medida en que representaba a un numeroso contingente estudiantil. Aunque en el transcurso 
de la segunda mitad del siglo xx su representación se fue reduciendo debido a los cierres y transformaciones de las instituciones que representaba, continuó siendo de importancia debido a que, por ejemplo, en la década de los sesenta era la representante oficial de 29 escuelas normales rurales que estaban ubicadas en los siguientes puntos del territorio nacional: Ayotzinapa, Guerrero; Zaragoza, Champusco y Teteles, en Puebla; El Mexe, Hidalgo; La Huerta y Tiripetío, en Michoacán; Mactumactzá, Chiapas; Palmira, Morelos; Perote, Veracruz; Panotla y Xocoyucan, en Tlaxcala; Reyes Mantecón y Tamazulapan, en Oaxaca; Roque, Guanajuato; Tenería, Estado de México; Atequiza, Jalisco; Cañada Honda, Aguascalientes; El Quinto, Sonora; Galeana, Nuevo León; Hecelchakan, Campeche; Jalisco, Nayarit; Saucillo y Salaices, en Chihuahua; San Diego, Tekax, Yucatán; San Macos, Zacatecas; Canatlán, Durango; Santa Teresa, Coahuila, y Tamatán, Tamaulipas (López Macedonio, 2016, pp. 338-339).

Las Escuelas Normales Rurales fueron un tipo de educación subsidiada que fue impulsada por el Estado luego de que la revolución mexicana se hiciera gobierno; se erigieron como una oferta educativa que ofreció un sistema de internado para jóvenes del medio rural; espacio del país que, durante décadas, concentró a la mayoría de la población que habitaba el territorio nacional, a la que se deseaba organizar y gobernar en la nueva lógica pretendida por la clase política revolucionaria.

A partir de la presidencia de Lázaro Cárdenas y de la creación de la FECSM se exigió que los matriculados en este tipo de instituciones comprobaran su origen humilde, con el fin de cobijar en sus aulas sólo a los jóvenes que no tuvieran posibilidad de costearse sus estudios profesionales. Este tipo de educación subsidiaba por el Estado revolucionario le dio techo, alimento y estudio a un numeroso contingente de jóvenes de las comunidades rurales. Les concedió la oportunidad de encontrar en la carrera magisterial una opción de vida a tal grado que, en la actualidad, un gran número de la población mexicana ha tenido en la familia o al menos un conocido con la profesión de maestro normalista; por lo que tampoco es fortuito que en México exista el sindicato magisterial más numeroso de América Latina. Y es que, a través de la educación, los gobiernos revolucionarios crearon oportunidades de mejoramiento social y económico para la mayoría de la población que entonces habitaba el medio rural, ya que: "ninguna clase dirigente podría prosperar en los albores del siglo xx sobre una base campesina pobre y sin posibilidades de mejoramiento social y económico" (Zea, 1963, pp. 16-17); esto lo tuvieron muy en cuenta los gobiernos revolucionarios. 
Los estudiantes matriculados en las Escuelas Normales Rurales permanecían internados seis años. Se recibían adolescentes de entre doce y trece años de edad a los cuales, en algunos casos, se les ofrecía un curso para que concluyeran la primaría con su debida certificación. Enseguida pasaban a cursar la secundaria $y$, al concluir esta, ingresaban al ciclo profesional para cursar la carrera de maestro normalista. Es importante señalar que, aunque todos los estudiantes matriculados en las Escuelas Normales Rurales eran automáticamente militantes de la FECSM, sólo los estudiantes del ciclo profesional eran los encargados de dirigirla. Durante la etapa de internado recibían vestido, calzado, así como una beca de alimentación y otra denominada "pre" para que sufragaran sus gastos los días que tenían permitido salir de paseo o visitar a sus familiares. Algunas escuelas llegaron a contar incluso con alberca, pero también había las que contaban apenas con los servicios básicos para funcionar. Durante los seis años que permanecían internados, los estudiantes matriculados en las Escuelas Normales Rurales, además del subsidio del gobierno federal para vivir y estudiar en dichos centros educativos, gozaban de la prerrogativa de que, al egresar, obtenían una plaza de trabajo, así como su militancia automática en el Sindicato Nacional de Trabajadores de la Educación (SNTE), que se convirtió, a partir de 1943 y durante décadas, en el operador político del Partido Revolucionario Institucional (PRI). Es importante añadir que este sistema funcionó así mientras la FECSM se mantuvo como la mediadora y representante oficial de los estudiantes normalistas rurales ante la SEP; es decir, mientras se mantuvo como portavoz de las bondades del régimen posrevolucionario en el medio rural.

La FECSM es una de las organizaciones estudiantiles más longevas que existen en México, por lo que ha sido testigo del largo proceso de transformaciones que ha encarado este país durante los siglos XX y XxI. Entre 1935 y 1969 fue reconocida por las autoridades de la SEP como la representante oficial de los estudiantes normalistas rurales. La educación subsidiada que los internados de las Escuelas Normales Rurales ofrecieron a los adolescentes y jóvenes del medio rural, abrieron la ruta de la movilidad ascendente a millones de mexicanos que participaron en sus programas de educación y capacitación durante el siglo xx. Estas escuelas especiales para los adolescentes y jóvenes del campo, que la FECSM representaba, fueron proyectadas en las primeras décadas del siglo xx para promover la formación de una clase campesina alfabetizada y organizada en cooperativas productivas para que fuera la base política y social de los gobiernos revolucionarios, así como la beneficiaria de la reforma 
agraria, una de las promesas esenciales de la revolución mexicana. Sin embargo, las expectativas de desarrollo nacional que comenzaron a vislumbrarse al final de los cuarenta, con sus retos de industrialización a costa del proyecto agrario y conducidos por una nueva clase política gobernante, terminaron por convertir las expectativas de desarrollo nacional agrario en promesas y dádivas relacionadas con los procesos electorales, las cuales coadyuvaron a sostener la estructura política corporativa del partido hegemónico posrevolucionario. La FECSM participó en estos y en muchos otros procesos de cambio. En la historia reciente, por ejemplo, tiene sentido referir que los tres estudiantes asesinados y los 43 que fueron desaparecidos la noche del 26 de septiembre de 2014 en la ciudad guerrerense de Iguala, además de estar matriculados en la Escuela Normal Rural "Isidro Burgos" de Ayotzinapa, Guerrero, eran militantes de la FECSM. Estos indignantes acontecimientos, que siguen a la espera de ser esclarecidos, nos refieren la pertinencia de hacer visible, en el medio académico, trabajos relacionados con el universo normalista rural que, como se advierte en el título de este trabajo, tiene muchas áreas de estudio por explorar. En este artículo dedicaremos espacio para explicar el posicionamiento de los estudiantes normalistas rurales organizados en la FECSM en el conflicto internacional de la guerra fría, un tema inédito y de suma importancia para la compresión de la historia política y social de la segunda mitad del siglo xx.

\section{LA FECSM, LOS REPRESENTANTES \\ DE LA INTERNACIONAL COMUNISTA EN MÉXICO Y EL GOBIERNO DE LÁZARO CÁRDENAS}

La FECSM nació como una iniciativa del magisterio normalista rural que militaba en el Partido Comunista Mexicano (PCM), que fue lanzada en vísperas del ascenso de Lázaro Cárdenas a la presidencia de la república, pero fue ocho meses después de que Cárdenas asumiera el mandato que fue reconocida como la representante nacional de los estudiantes de las escuelas que formaban maestros rurales en el medio campesino. Desde julio de 1935 hasta 1969 las autoridades de la SEP darían su reconocimiento y patrocinio a todas las actividades y demandas que la FECSM solicitó. Sin embargo, la alianza del PCM con el gobierno de Lázaro Cárdenas no fue una decisión fácil de tomar para ese partido. Esto se puede inferir, inicialmente, a través del nombre concedido a la iniciativa de organización estudiantil. Aquí es importante advertir que 
desde que fue planteada la idea de organizar una Federación de Estudiantes Campesinos en agosto de 1934, hasta que esta se concretó en julio de 1935, cuando la Federación realizó su Primer Congreso Nacional con el respaldo oficial de la SEP y logró obtener su reconocimiento, dicha organización estudiantil sólo refirió en su nombre a la clase social que representaba pero no hizo explícito el adjetivo socialista; es decir, el nombre del proyecto educativo oficial del gobierno federal, que entonces llevó el nombre de educación socialista. La Federación de Estudiantes Campesinos añadió el adjetivo socialista a su nombre sólo después de que el PCM aceptó dar su colaboración al gobierno de Lázaro Cárdenas, lo cual sucedió hasta febrero de 1936. Al respecto, es pertinente señalar que antes de febrero de 1936, el PCM se resistía a poner en marcha la nueva política que la Internacional Comunista había hecho oficial durante su Séptimo Congreso, realizado en Moscú entre julio y agosto de 1935. De acuerdo con las resoluciones de este congreso, los partidos comunistas debían aliarse con los gobiernos de sus respectivos países para crear juntos un movimiento antifascista y antiimperialista sin miramiento de clase. Las resoluciones de este congreso fueron muy claras en ese sentido. Por ejemplo, en el caso de México, el PCM debía aliarse con el Estado y el Partido Nacional Revolucionario (PNR) para crear, con los sindicatos que el líder socialista mexicano Vicente Lombardo Toledano dirigía y con los que el PCM dirigía, un amplio frente popular antifascista y antiimperialista en el que cupieran todas las clases sociales. El cambio era drástico, y como le escribió a Hernán Laborde, un militante del PCM en octubre de 1935, "aún por mucho tiempo tendremos que batallar para conseguir su asimilación efectiva por toda la masa del P.”. Y es que la Internacional Comunista no adjudicó el encargo de dirigir el Frente Popular Antifascista Mexicano al secretario general del PCM, Hernán Laborde, sino a Vicente Lombardo Toledano. De hecho, Lombardo Toledano asistió al Séptimo Congreso de la Internacional Comunista como invitado especial; pero Hernán Laborde no recibió tal deferencia y sólo asistió como un representante más de un partido comunista adscrito a la Internacional Comunista (Spenser, 2007, pp. 59-69). Sin embargo, el PCM terminó por alinearse a la nueva política que la Internacional Comunista demandaba. Dio muestras claras y contundentes de su adhesión a esa política en el transcurso de 1936, cuando el presidente Cárdenas ofreció a los trabajadores organizados una mayor participación en las instituciones y empresas gubernamentales de las que formaban parte, y cuando patrocinó su unificación económica y política en la Confederación de Trabajadores de México (стм), constituida en febrero de 1936 con 
Vicente Lombardo Toledano en la Secretaría General; un proceso de unificación obrera en el que el PCM tuvo una importante y decisiva colaboración.

A la par de las labores de unificación obrera dirigidas por los representantes de la Internacional Comunista en México, Lombardo Toledano y Hernán Laborde, podemos también observar la filiación que los estudiantes normalistas rurales lograron concretar en el gobierno de Lázaro Cárdenas con la guía de sus profesores, militantes del Partido Comunista. La Federación de Estudiantes Campesinos se adhirió oficialmente a la política del Frente Popular en diciembre de 1936, durante su Segundo Congreso Nacional que fue realizado en la Escuela Normal Rural de Tenería, Estado de México. A partir de entonces, las referencias que sobre este congreso se resguardaron en el AHSEP, se refieren a la Federación de Estudiantes Campesinos con el adjetivo socialista en su nombre. En dicho congreso, desde entonces, la FECSM se declaró a favor del Frente Popular Mexicano y manifestó su disposición abierta de apoyar al gobierno del presidente Cárdenas mientras este mantuviera una línea progresista. Cabe destacar que, entre las resoluciones de su Segundo Congreso Nacional, la FECSM solicitó como punto especial la creación de una escuela campesina en la zona de La Laguna y demandó que esta contara con personal de ideas revolucionarias. Es pertinente advertir que, en esta región geográfica del país, el PCM desempeñó un papel decisivo en la organización de los jornaleros agrícolas y en la exigencia del reparto de las tierras algodoneras, mismo que había sido decretado por el presidente Cárdenas desde octubre de 1936 (Carr, 1996, pp. 93-113). La FECSM también manifestó abiertamente su apoyo a todas las reformas impulsadas por el gobierno cardenista y reafirmó su posición como defensora oficial del proyecto educativo gubernamental. Este reconocimiento de la FECSM y los derechos concedidos a los estudiantes a través de ella fueron, sin duda, una conquista estudiantil, pero también un elemento imprescindible en la política corporativa del gobierno cardenista debido al contexto de violenta oposición a las reformas educativa, obrera y agraria que, desde julio de 1935, tras el conflicto con el expresidente Plutarco Elías Calles, el presidente Cárdenas impulsó de forma decisiva en alianza con los obreros, los campesinos, el magisterio y con los estudiantes, quienes también fueron incluidos en la política corporativa del gobierno cardenista. Esta política convirtió a todos estos sectores sociales en actores de la política mexicana.

La historiografía ha destacado el sitio cardinal que los obreros, los campesinos, e incluso el magisterio, ocuparon en la política corporativa del gobierno cardenista. Sabemos que luego de consolidar su alianza con los obreros en 
la Стм, el presidente Cárdenas requirió de su apoyo para sustituir al Partido Nacional Revolucionario (PNR), que había creado Plutarco Elías Calles en 1929, por el Partido de la Revolución Mexicana (PRM), iniciativa que se concretó en marzo de 1938. También sabemos que el presidente Cárdenas promovió la unificación de los campesinos en una organización aparte de la Стм y que el 28 de agosto de 1938 asistió a la ceremonia en la que fue constituida la Confederación Nacional Campesina (CNC), en la que fue nombrado secretario general el profesor normalista Graciano Sánchez Romo. La CNC proclamó actuar dentro de un franco espíritu de lucha de clases, pero aceptando su cooperación con el Estado, lo cual deja entrever la participación destacada que los representantes de la Internacional Comunista en México tuvieron en la construcción de la política corporativa del presidente Lázaro Cárdenas, siguiendo aquellos la línea establecida por la Internacional. Sabemos que en el comité central del partido creado por Cárdenas estuvieron representados los campesinos y los obreros, con estos últimos incluidos los maestros, y que, adicionalmente a las centrales obrera y campesina, fue incorporado el sector popular a través de la Confederación Nacional de Organizaciones Populares (CNOP), que fue constituida en 1943 en la administración de Manuel Ávila Camacho, quien sería el único candidato a la presidencia de la república del partido creado por Cárdenas. La CNOP fue constituida bajo el liderazgo del joven abogado Carlos Alberto Madrazo Becerra, colaborador de Vicente Lombardo Toledano. En ella se unificó a todos aquellos grupos que no eran admisibles en las confederaciones obrera y campesina; reunió en su seno a grupos dedicados al comercio, al transporte, al turismo, vendedores ambulantes, expendedores, vendedores de billetes de lotería y profesionistas de diversos ramos (Reyna, 2009, p. 36).

Pero, ¿qué pasó con los estudiantes en ese proceso? Al respecto, debemos decir que los estudiantes de las universidades públicas y de las escuelas normales, rurales y urbanas que respaldaron la educación socialista, proyecto educativo que, por cierto, fue defendido por Vicente Lombardo Toledano frente a la impugnación de Antonio Caso, también se organizaron en una central. Esta central estudiantil llevó por nombre Confederación de Jóvenes Mexicanos (сјм) y, a diferencia de las centrales obrera y campesina, no ocupó un lugar en el comité central del partido creado por el presidente Cárdenas. Esto no era de extrañar; la idea arraigada de la obediencia irrestricta de los hijos hacia sus padres se hizo manifiesta en la cultura política de esa época. En el artículo 17 de su declaración de principios, el partido creado por el presidente Cárdenas se comprometió a "trabajar para que al sector juvenil del país se le reconozcan 
sus derechos específicos y se esforzará para que la juventud mexicana se organice y unifique". Congruente con su promesa, este partido dio su patrocinio y respaldo para que las juventudes leales a Cárdenas y a la educación socialista se unificaran en la cJM, la cual fue reconocida como su sector juvenil (Arriaga, 1962, pp. 62-63). Si bien la juventud era considerada como un sector que le debía obediencia absoluta a sus mayores, por considerarse que estos últimos eran los que estaban naturalmente aptos para conducir los destinos tanto de las familias como del país, el sistema político mexicano advirtió el potencial político de los estudiantes y procedió a incluirlos en la política corporativa, mientras estos acataran, sin cuestionar, el camino sugerido por sus mayores. Sobre la creación de la CJM, el político priista Agustín Arriaga Rivera señala que, al crearse el Partido de la Revolución Mexicana (PRM), es decir, el partido creado por el presidente Cárdenas, surgió paralelamente, y como su sector juvenil, una nueva organización, sin duda la más fuerte en la compleja vida de los movimientos juveniles. Advierte que el PRM, a través del sector juvenil, realizó una intensa labor de unificación en todos los estados de la república para llegar a su constitución (Arriaga, 1962, p. 43). En esta importante labor destacó también la participación de Carlos Alberto Madrazo Becerra, quien se convirtió en el primer presidente que tuvo la CJM. Madrazo Becerra se había iniciado en política en su natal Tabasco militando en las juventudes leales a Tomás Garrido Canabal, que le valieron una beca para estudiar en la ciudad de México. Como estudiante de la Escuela Nacional Preparatoria se sumó a la defensa de la iniciativa de reforma al artículo tercero constitucional encabezada por Vicente Lombardo Toledano en el Primer Congreso de Universitarios Mexicanos, que fue celebrado en la ciudad de México del 8 al 14 de septiembre de 1933. Madrazo Becerra fue quien llamó a constituir la Confederación de Estudiantes Socialistas de México como escisión de la Confederación Nacional de Estudiantes, esta última constituida con miembros de todas las universidades del país desde 1927, cuyos dirigentes habían respaldado la impugnación de Antonio Caso a la educación socialista en el mencionado congreso universitario. Es importante señalar que la Confederación de Estudiantes Socialistas había estado presente en el Primer Congreso Nacional que la FECSM celebró en julio de 1935 con el respaldo y patrocinio de las autoridades educativas del gobierno cardenista. ${ }^{1}$

${ }^{1}$ Primer Congreso de la Federación de Estudiantes Campesinos Socialistas de México, julio de 1935. Exp. 509:4-8-8-30. Archivo Histórico de la Secretaría de Educación Pública (en adelante AHSEP), México. 
La Confederación de Jóvenes Mexicanos (сјм) -también llamada el sector juvenil del Partido de la Revolución Mexicana (PRM) - fue constituida en una ceremonia oficial realizada el 15 de abril de 1939 en el Palacio de Bellas Artes de la ciudad de México, con una asistencia de 5000 delegados juveniles de toda la república (Arriaga, 1962, p. 47). Al día siguiente de haberse constituido, el periódico La Voz de México publicó una nota que refería los nombres de las organizaciones que se habían reunido en el Palacio de Bellas Artes para unificarse en la CJM, entre las que se encontraba la FECSM (Cuevas, 1984, pp. 55-56). El nacimiento de la cJM debe situarse en el marco de la construcción de la política corporativa del gobierno cardenista que se erigió en alianza con los representantes de la Internacional Comunista en México, la cual se fue fraguando oficialmente, desde febrero de 1936, con el nacimiento de la стм, pasando por la fundación del PRM, en marzo de 1938, con la unificación de las organizaciones campesinas en la CNC, en agosto de 1938, y, finalmente, con la unificación de las organizaciones estudiantiles que respaldaron la educación socialista, en abril de 1939, en la que los estudiantes de las Escuelas Normales Rurales, organizados en la FECSM, también fueron incorporados con la guía de sus maestros que militaban en el Partido Comunista Mexicano (PCM). Las organizaciones estudiantiles que estuvieron adheridas a la сјм consiguieron, durante décadas, éxitos y fracasos para el sector estudiantil universitario y normalista que representaron. Éxitos que dan la impresión de su importancia estratégica para el mantenimiento de la paz social y política corporativa fraguada desde el cardenismo. La FECSM formó parte de esta política corporativa del gobierno cardenista al unificarse en la CJM, el sector juvenil del PRM.

Sin embargo, en el transcurso de las décadas de 1940 y 1950, las instituciones y los pactos políticos corporativos fraguados en el gobierno cardenista se fueron transformando a la par que también lo hicieron la clase política gobernante, sus expectativas de desarrollo nacional, así como la arena política internacional, que había favorecido la unidad a toda costa entre el socialismo y el capitalismo, en vísperas y durante la segunda guerra mundial.

\section{LA FECSM Y EL NUEVO RUMBO IDEOLÓGICO DE LA REVOLUCIÓN MEXICANA}

La paulatina pero exitosa incorporación de la FECSM a la política corporativa del Estado mexicano fue resultado de las alianzas políticas internacionales 
fraguadas entre los representantes de la Internacional Comunista en México y el gobierno de Lázaro Cárdenas. Esta política se nutrió de los pactos políticos corporativos con los obreros, los campesinos, el magisterio y con los estudiantes, mismos que fueron promovidos y encabezados tanto por el líder socialista Vicente Lombardo Toledano y el partido comunista que dirigía Hernán Laborde. Estos pactos políticos corporativos, como el que se estableció con la FECSM al reconocerla, por ejemplo, como la representante nacional de los estudiantes de las Escuelas Normales Rurales ante las autoridades de la SEP, constituyeron la estructura corporativa que después conocimos y con la que el partido hegemónico revolucionario gobernó este país durante gran parte del siglo xx. Pero la transmisión de esa estructura corporativa implicó varias y profundas transformaciones. Y es que después del gobierno cardenista se fue posicionando en la presidencia de la república una clase política mexicana distinta de aquella que había conducido los destinos del país entre 1917 y 1940. Distinta porque esta ya no provenía de las filas de los ejércitos que lucharon a favor de la revolución mexicana, sino de las aulas universitarias. Con excepción de Ávila Camacho y de Ruiz Cortines, que no realizaron estudios universitarios, los presidentes Miguel Alemán Valdés, Adolfo López Mateos, Luis Echeverría Álvarez, José López Portillo y Gustavo Díaz Ordaz estudiaron la carrera de abogado en la universidad pública. Salvo Díaz Ordaz, que lo hizo en el entonces llamado Colegio del Estado de Puebla, el resto obtuvo el grado en la Universidad Nacional Autónoma de México (UnAM) y ninguno realizó posgrados en universidades estadunidenses como sí lo haría la generación de presidentes mexicanos posterior a 1982. Es decir, las cosas cambiaron cualitativamente después de que Lázaro Cárdenas dejó la presidencia de la república.

La UNAM, que había sido el principal centro opositor al proyecto educativo oficial del gobierno cardenista, formó a la mayoría de los abogados que ocupó la presidencia de la república entre 1946 y 1982, así como a buena parte de los burócratas de alto nivel. A la lista de cambios habría que agregar la cancelación de la educación socialista en diciembre de 1945, que fue derogada por iniciativa de Jaime Torres Bodet con el apoyo del Sindicato Nacional de Trabajadores de la Educación (SNTE), agrupación que se constituyó en diciembre de 1943 en el Palacio de Bellas Artes de la ciudad de México y que sustituyó al Sindicato de Trabajadores de la Enseñanza de la República Mexicana (STERM), adscrito al partido creado por el expresidente Cárdenas. El abandono de la lucha de clases como discurso oficial del gobierno implicó 
un cambio sustancial no sólo en el discurso, sino también en el sentido y rumbo de las instituciones gubernamentales, al ser marginados de ellas aquellos que habían sido los principales colaboradores de Cárdenas durante su mandato y que habían contribuido a edificar el Partido de la Revolución Mexicana (PRM) y su lema: "Por una Democracia de los Trabajadores". En enero de 1946 se realizó la transformación oficial del PRM al Partido Revolucionario Institucional (PRI), por lo que ahora su lema expresaba los retos de la nueva clase política mexicana, la que ahora se comprometía a lograr la "Democracia y Justicia Social", dar continuidad al compromiso revolucionario con las mayorías, continuar la reforma agraria, y mantener la preeminencia del Estado en la economía. En sus estatutos, el nuevo partido se definió como una asociación política nacional integrada por obreros y campesinos organizados, trabajadores independientes, empleados públicos, cooperativistas, artesanos, estudiantes, profesionales, comerciantes en pequeño y demás elementos afines en tendencias e intereses, que aceptaran los principios de la revolución mexicana. Entre sus objetivos, el PRI planteó alcanzar el poder público por la vía democrática y dentro de la ley, emprendiendo "su actuación pública por medios pacíficos y con el más estricto apego a las instituciones nacionales, sin subordinar sus actos a ninguna organización internacional ni depender ni afiliarse a partidos políticos extranjeros".

Para entonces, la guerra en Europa había concluido, y aunque el gobierno mexicano manifestó conducirse mediante una política neutral y no alineada, los militantes del recién nacido PRI marginaron a los representantes de la Internacional Comunista en México de la vida pública gubernamental. Después de todo, y a pesar del discurso del Estado mexicano que apeló a la neutralidad durante la guerra fría, el país vecino era Estados Unidos de América y no la Unión Soviética. Sin embargo, la obra corporativa que los representantes de la Internacional Comunista en México habían contribuido a edificar, fue conservada por el PRI, aunque adaptada a los nuevos requerimientos nacionales y a los nuevos retos internacionales que supuso el fin de la segunda guerra mundial. La nueva clase política cobijada por el PRI fincó sus expectativas de desarrollo nacional en las ciudades y en la posibilidad de hacer de México un país industrial. Estos nuevos horizontes posicionaron al espacio urbano y a la industria en el centro de desarrollo nacional, por lo que, aquella política educativa que había creado una escuela especialmente dirigida a formar maestros campesinos, fue sustituida por una nueva política educativa oficial, la cual orientó los programas de estudio hacia la formación 
de obreros calificados que el desarrollo industrial del país exigía. A partir de entonces, ya no se requirió de escuelas que formaran maestros campesinos, sino de maestros que respondieran a esas nuevas expectativas de desarrollo.

Con la derogación constitucional de la educación socialista, la creación de un nuevo partido de la revolución mexicana y las nuevas expectativas de desarrollo nacional, la Federación de Estudiantes Campesinos Socialistas de México tuvo necesariamente que adaptarse a una nueva realidad institucional en la cual, de acuerdo con los estatutos del PRI, los estudiantes también fueron incluidos. En este sentido, la FECSM recibió un trato que le confirmó su lugar en la nueva realidad institucional. Por ejemplo, se le continuó reconociendo personalidad jurídica para asumir sus actividades de representación estudiantil, confiriéndole obligaciones, pero también derechos que le garantizaron el respaldo de todas sus actividades y demandas ante la sEP. También conservó su estatus de representante oficial de una comunidad escolar muy cercana a las comunidades campesinas; comunidades rurales a las que se les reconocieron derechos agrarios mediante su unificación en la Confederación Nacional Campesina. Durante décadas, estas comunidades campesinas se erigieron como la base política corporativa del PRI en el medio rural. Los estudiantes de las Escuelas Normales Rurales tenían lazos familiares con esas comunidades y, por lo tanto, eran solidarias con sus problemas; en muchos casos, los egresados de las Escuelas Normales Rurales llegaron a convertirse en funcionarios estatales o municipales, pero también fueron sus asesores e intermediarios, situación que impidió, durante muchos años, que problemas pequeños como, por ejemplo, la solicitud de pavimentación de una calle, llegaran a convertirse en grandes problemas; según me contó un exdirigente de la Fecsm. ${ }^{2}$ Además, en esta nueva realidad institucional estaban incluidos sus maestros, que eran parte del numeroso magisterio normalista que se había unificado en el SNTE, sindicato en el que pasaban a formar parte todos los egresados de las Escuelas Normales de manera automática, el que había respaldado la cancelación de la educación socialista y la fundación del PRI, situación que lo convirtió en un aliado político estratégico de este partido durante varias décadas del siglo xx.

Para adaptarse a la nueva realidad institucional, la FECSM emprendió una reforma a sus estatutos, los cuales constituyen una fuente sumamente

${ }^{2}$ Entrevista al ex dirigente de la Fecsm, Saúl López de la Torre, realizada por Mónica Naymich López Macedonio, ciudad de México, 28 de noviembre de 2012. 
ilustrativa de la respuesta que la organización estudiantil mostró ante las realidades políticas nacional e internacional, ya que le supuso nuevas alianzas y retos que le exigieron replantearse ideológicamente. Como respuesta a estos cambios, la FECSM ratificó una reforma a sus estatutos en su Décimo Primer Congreso Nacional, que fue realizado del 12 al 18 de septiembre de 1950 en la Escuela Normal Rural de Palmira, Morelos. Para los propósitos de este artículo sólo es necesario mencionar que, en los estatutos reformados, "que habrán de regir a todas las Sociedades de Estudiantes de las Escuelas Normales Rurales del país", no hay una sola mención al socialismo. Para entonces, la FECSM justifica su existencia como representante y organismo autorizado para resolver los problemas no sólo de los estudiantes normalistas rurales que en ella militan, sino también de las instituciones donde "nos educamos", y afirma que su "fin supremo" será defender "una educación democrática apegada a los principios de la revolución mexicana [...] y sin ninguna discriminación para la juventud campesina". ${ }^{3}$ Es decir, su discurso está abiertamente apegado al nuevo discurso institucional de la revolución mexicana hecha gobierno. A pesar de la derogación constitucional de la educación socialista, la organización estudiantil conservó el adjetivo socialista en su nombre porque, como me contó en una entrevista el maestro Pedro Chávez Sánchez, exdirigente de la fECSM, y actualmente profesor de la Escuela Normal Indígena de Cherán, Michoacán: "el socialismo no se negocia". ${ }^{4}$ A pesar de que el materialismo histórico dejó de ser la orientación educativa oficial en México desde diciembre de 1945, los estudiantes que han dirigido a la FECSM han conservado aquella ideología como fundamento de su organización y considerado al socialismo como una alternativa para la humanidad, rechazando el capitalismo que los excluye, lo cual, sin embargo, no se lee explícitamente en el cuerpo de sus estatutos oficiales de los años cincuenta; de lo que se desprende que la FECSM no ha sido la misma en su larga vida. De acuerdo con las declaraciones de algunos dirigentes de la FECSM del siglo XXI, se sabe que en las Escuelas Nor-

\footnotetext{
${ }_{3}^{3}$ Dirección Federal de Seguridad. Versión pública de la FECSM, tomo 1, Estatutos, p. 122. Archivo General de la Nación (en adelante AGN), México.

${ }^{4}$ Entrevista al maestro Pedro Chávez Sánchez, egresado en 2003 de la Escuela Normal Rural de Tiripetío Michoacán, realizada por Mónica Naymich López Macedonio, en el centro histórico de la ciudad de Morelia, Michoacán, el 9 de mayo de 2015, después de una marcha convocada por la sección estatal de la Coordinadora Nacional de los Trabajadores de la Educación, para manifestarse en contra de la reforma educativa impulsada por el entonces gobierno de Enrique Peña Nieto.
} 
males Rurales la organización estudiantil ha mantenido el materialismo histórico como programa de estudios alternativo al oficial y como su aparato de cohesión y reproducción ideológica. Esto mismo me lo confirmó el estudiante de la Escuela Normal Rural de Ayotzinapa, Guerrero, "Aquilino", en su calidad de secretario de relaciones exteriores del Comité Ejecutivo Nacional de la FECSM (periodo 2011-2012) quien, para este momento, debería ser egresado de aquella Normal Rural..$^{5}$ Además de cursar sus materias establecidas en el programa educativo oficial para formarse como maestros normalistas, los dirigentes estudiantiles han destinado un tiempo del día para estudiar el materialismo histórico, discurso que le ha dado unidad e identidad a la comunidad estudiantil formada en las Escuelas Normales Rurales, que conservan aún el sistema de internado y que reconocen la autoridad de la FECSM (FECSM, 2011-2012).

En suma, la FECSM se constituyó por iniciativa del magisterio que militaba en el PCM, y su afiliación al PRM, a través de la CJM, fue una consecuencia de la alianza de ese partido con el gobierno cardenista en el marco de la política del Frente Popular Antifascista Mexicano que promovió la Internacional Comunista y que el PCM secundó en México, en alianza con el socialista mexicano Vicente Lombardo Toledano. Es importante mencionar que, desde que la сJM inició actividades, su dirección quedó en manos de la corriente política que dirigía Lombardo Toledano, muestra de ello fue que su primer presidente fue Carlos Alberto Madrazo Becerra, estrecho colaborador de Lombardo. El PCM mantuvo su colaboración en la unidad fraguada en la CJM desde la creación de esta última, en 1939, hasta los albores de los años sesenta, lo que le permitió a la FECSM mantener su estatus de representante oficial de los estudiantes de las Escuelas Normales Rurales ante las autoridades de la sEP de los gobiernos de Miguel Alemán Valdés, Adolfo Ruíz Cortines, Adolfo López Mateos y Gustavo Díaz Ordaz, hasta el año de 1969.

${ }^{5}$ Entrevista a Aquilino, estudiante de la Escuela Normal Rural "Isidro Burgos", secretario de Relaciones Exteriores de la FECSM, periodo 2011-2012, realizada por Mónica Naymich López Macedonio, ciudad de México, 2011. 


\section{EL LUGAR DE LA FECSM EN EL CONTEXTO POLÍTICO INTERNACIONAL DE LA GUERRA FRÍA}

Cuando los respectivos gobiernos de Estados Unidos de América y de la Unión de Repúblicas Socialistas Soviéticas (URRS) protagonizaban un peculiar conflicto internacional -que el periodista estadunidense Walter Lippmann denominó cold war- hacía poco más de una década que la FEcSM se había constituido. Para entonces, ya colaboraba con el régimen posrevolucionario a través de su militancia en la сјM, la central estudiantil que, como la obrera y la campesina, creadas durante el gobierno cardenista, fue reconocida por el Partido Revolucionario Institucional para escuchar y respaldar las demandas de su gremio. La adaptación de la FECSM a esas nuevas realidades políticas nos permite advertir la complejidad de las alianzas que el Estado posrevolucionario mantuvo vigentes y cómo estas funcionaron.

En la cjM confluían las distintas corrientes de la izquierda mexicana de la época, pero la que tenía el control de la central estudiantil era la corriente encabezada por Vicente Lombardo Toledano. Para entonces, este último se encontraba marginado de la vida pública gubernamental, pero con el suficiente poder persuasivo para mantenerse vigente en la oposición al PRI y para fundar, en 1948, el Partido Popular. Además, Lombardo Toledano había logrado posicionarse como una figura emblemática de la izquierda latinoamericana. Por designación de la Internacional Comunista era, desde 1938, secretario general de la Confederación de Trabajadores de América Latina (CTAL) y llegó a ser vicepresidente de la Federación Sindical Mundial, que fue constituida en octubre de 1945. La CTAL, organismo que logró unificar a las centrales y organizaciones obreras de América Latina, había sido creada cuando Lombardo Toledano se desempeñaba como secretario general de la Confederación de Trabajadores de México en el gobierno de Lázaro Cárdenas. A pesar de su marginación de la vida gubernamental mexicana, logró mantener su estatus de secretario general de la CTAL desde su creación hasta su disolución en 1963. Abiertamente alineado a la alternativa que la Unión Soviética ofrecía al mundo, Lombardo Toledano se erigió como una figura respetada y admirada, no sólo en los círculos políticos de la izquierda sindicalista latinoamericana, sino también entre los dirigentes de las organizaciones estudiantiles mexicanas que estaban unificadas en la сJM, las cuales reconocieron y enunciaron en sus estatutos el respeto que les merecía su movimiento político. Por ejemplo, en los estatutos del organismo estudiantil de las Escuelas Normales Rurales se 
establecía que, además de desempeñar tareas de reclutamiento a favor de la CJM, "la central máxima nuestra", se atribuía a la Secretaría de Acción Obrera y Campesina la encomienda de "ayudar a los obreros y a los campesinos a resolver sus problemas", brindándoles orientación para que estos presentaran, por medio de la сјM, a "las organizaciones representativas de la clase trabajadora de México y de la América Latina", las cuales eran "la Unión General de Obreros y Campesinos de México (UGocm) y la Confederación de Trabajadores de América Latina (CTAL)"; ${ }^{6}$ ambas bajo el liderazgo de Vicente Lombardo Toledano. Además de la Secretaría de Acción Obrera y Campesina, el Comité Ejecutivo Nacional de la FECSM funcionaba con una Secretaría General, Secretaría de Actas y Acuerdos, Secretaría de Finanzas, Secretaría de Organización, Secretaría de Prensa y Propaganda, Secretaría de Conflictos, Secretaría de Acción Femenil, Secretaría de Acción Juvenil, Secretaría de Relaciones con ex Alumnos, Secretaría de Asuntos Indígenas y la Secretaría de Acción Sindical y Política. ${ }^{7}$ Es importante mencionar que cada Escuela Normal Rural representada en la FECSM contaba con un comité ejecutivo con esa misma estructura y, por lo menos, un representante de ese comité local era incluido en el Comité Ejecutivo Nacional, con el afán de que todas las escuelas del sistema estuvieran representadas en dicha federación estudiantil. La FECSM organizaba congresos nacionales de manera periódica para renovar a su dirigencia, a los cuales asistían funcionarios de los tres niveles de gobierno -presidentes municipales, gobernadores, diputados y funcionarios de la SEPpara inaugurarlos, lo que expresa parte del funcionamiento del pacto político corporativo que existía entre dicha organización estudiantil y el Estado mexicano posrevolucionario (López Macedonio, 2016).

Si bien en gran medida el protocolo con el que venían funcionando las alianzas políticas corporativas fraguadas en el gobierno cardenista continuaron siendo reproducidas en la era de los gobiernos del PRI, parte de su discurso y de sus metas tuvieron que ser replanteadas en sintonía con el desenlace de la segunda guerra mundial, que implicó el triunfo de los países aliados sobre las potencias del eje.

${ }^{6}$ Dirección Federal de Seguridad. Versión Pública de la FEcsm, t. 1, Atribuciones de la Secretaría de Acción Obrera y Campesina, p. 129. AgN, México.

${ }^{7}$ Dirección Federal de Seguridad. Versión Pública de la FEcsm, t. 1, Estatutos, pp. 126129. AGN, México. 
El discurso que la FECSM utilizó en su declaración de principios en el periodo de la posguerra refiere explícitamente su posición política e ideológica en el conflicto internacional de la guerra fría. Con alusiones al discurso oficial de la Internacional Comunista de la década de 1930, la FECSM señala que: "con los demás sectores revolucionarios y progresistas de México" luchará "por la total liquidación de las fuerzas que intentan regresar a México a tiempos obscurantistas" y refiere que estas son "el Partido Acción Nacional, el Sinarquismo con su careta de Fuerza Popular y los Dorados”, a los cuales identifica como los satélites del fascismo en México. También sitúa, entre sus "enemigos de ultramar", al imperialismo internacional, el Plan Truman, el Plan Clayton y el Plan Marshall "que tratan de retardar y malograr el progreso Nacional e internacional", así como "aniquilar la sabia robusta de la juventud" mexicana y del mundo "que pugna por su liberación". ${ }^{8}$ Es importante advertir que esta Federación reconoció sólo un imperialismo internacional: el estadunidense, y al hacerlo se posicionó ideológicamente al lado del movimiento por la paz "anticapitalista", que abanderaron organizaciones internacionales vinculadas al bloque soviético como la Federación Mundial de la Juventud Democrática (FMJD) y la Unión Internacional de Estudiantes (UIE), de las que la FECSM fue miembro fundador a través de su militancia en la cJM. Sobre su militancia política internacional, la FECSM aludió lo siguiente: "los objetivos que movilizaron a los pueblos y a la juventud de todos los países democráticos en la segunda guerra mundial fueron los de lograr una Paz para todos los pueblos de la tierra" y, en ese sentido, "la juventud estudiosa del campo luchará por la realización de los anhelos de paz, justicia y de libertad". La FECSM se define abiertamente antiimperialista y señala que "combatirá a los enemigos de la Independencia Nacional y del progreso de nuestra Patria Mexicana". ${ }^{9}$ Entre sus finalidades, menciona que luchará "por la proscripción de todas las armas de exterminio" como la bomba atómica, y que se opondrá a toda agresión hacia "los países débiles". Luchará a favor de la democracia, la paz mundial, la libertad y el progreso, al lado de la CJM, FMJD y la UIE, a las cuales entregó periódicamente una cuota de representación sindical. ${ }^{10} \mathrm{La}$

${ }^{8}$ Dirección Federal de Seguridad. Versión Pública de la fecsm, t. 1, Estatutos, p. 123. AGN, México.

${ }_{9}$ Dirección Federal de Seguridad. Versión Pública de la Fecsm, t. 1, Estatutos, p. 123. AGN, México.

${ }^{10}$ Dirección Federal de Seguridad. Versión Pública de la FecsM, t. 1, pp. 123, 125 y 133. AGN, México. 
Secretaría de Finanzas de la FECSM era la encargada de hacer cumplir esa y otras aportaciones sindicales de sus agremiados. ${ }^{11}$

La Federación Mundial de la Juventud Democrática fue constituida el 10 de noviembre de 1945 en Londres, como resolución de la Conferencia Mundial Juvenil, la cual había sido convocada inicialmente por las juventudes de los países aliados y había agrupado a representantes estudiantiles de diferentes tendencias políticas y religiosas, procedentes de 63 países. Desde entonces, este organismo internacional se comprometió a unificar a la juventud para trabajar a favor de la paz, la libertad, la democracia, la independencia y la igualdad en cualquier lugar del mundo. Sin embargo, casi enseguida de su constitución, las organizaciones de los países capitalistas se retiraron de su seno, arguyendo su asociación con partidos comunistas y socialistas alineados a la Unión Soviética. La UIE fue constituida el 27 de agosto de 1946, en Praga, Checoslovaquia, como un movimiento juvenil antifascista y como resolución del Congreso Mundial de Estudiantes. La FMDJ y la UIE fueron, a su vez, miembros del Consejo Mundial de la Paz; organismo que fue constituido en 1949 con el objetivo explícito de promover la coexistencia pacífica y el desarme nuclear. El Consejo Mundial de la Paz promovió, a través de sus agremiados en todo el mundo, la proliferación de movimientos pacifistas y manifestaciones de protesta en contra del imperialismo estadunidense, y se avocó a crear empatías hacia la Unión Soviética y una actitud crítica hacia la política imperialista de Estados Unidos. Sólo tras la caída de la Unión Soviética se supo contundentemente que el Consejo Mundial de la Paz había sido creado y financiado por el Estado soviético (World Peace Council (1989). Estas organizaciones internacionales, que fueron creadas después de la segunda guerra mundial, promovieron por el mundo la coexistencia pacífica a través de congresos y otras actividades de vinculación internacional, donde también abonaron a la idea de que el planeta Tierra podría ser algún día la patria del comunismo y/o socialismo.

La FMJD y la UIE organizaron desde 1947 el Festival Mundial de la Juventud Democrática y los Estudiantes. Durante la guerra fría, las ediciones de este Festival se celebraron en Estados socialistas, con excepción de las realizadas en Austria, en 1959, y en Finlandia, en 1962 -ambos neutrales-; la edición más concurrida fue la realizada en Moscú en 1957. Tras la caída del bloque del

${ }^{11}$ Dirección Federal de Seguridad. Versión Pública de la FEcsm, t. 1, Atribuciones de la Secretaría de Finanzas, p. 127. AgN, México. 
Este, la FMJD sufrió un duro golpe que le impidió conmemorar el Festival hasta 1997, cuando logró realizarse en La Habana, Cuba. ${ }^{12}$ Desde entonces, estos se han realizado con cierta regularidad: en 2001 fue en Argel, Argelia; en 2005 en Caracas, Venezuela; en 2010 en Tshwane, Sudáfrica; en 2013 fue en Quito, Ecuador, y en 2017 en Sochi, Rusia.

Mientras destacadas figuras políticas e intelectuales mexicanas como Jaime Torres Bodet, que dirigió la UNESCO, con sus metas de justicia social realizables en el capitalismo, en el Consejo Mundial de la Paz militaron las figuras más emblemáticas del nacionalismo revolucionario. Por ejemplo, Heriberto Jara llegó a ser presidente del Comité Mexicano de la Paz, mientras que el expresidente Lázaro Cárdenas recibió el Premio Stalin de la Paz en 1955, un galardón que en el mundo de los países comunistas pretendía ser el equivalente al Premio Nobel de la Paz. El Premio Stalin de la Paz fue concedido a individuos que, a criterio del Consejo, "hubieran contribuido a la causa de la paz entre los pueblos" ${ }^{13}$ Es pertinente añadir que esas destacadas figuras del Partido de la Revolución Mexicana habían encontrado cabida en el PRI; otros, como Vicente Lombardo Toledano y los militantes del Partido Comunista Mexicano, no cupieron formalmente en ese instituto político. Tras su marginación de la estructura corporativa heredada del PRM al PRI, algunos de los colaboradores del cardenismo se movieron a la oposición política y crearon sus propias instituciones políticas.

Un ejemplo emblemático fue Vicente Lombardo Toledano quien, tras su marginación y posterior expulsión de la dirección de la СтM, creó el Partido Popular, mostrando de esta manera la determinación de mantener su lucha por el socialismo en México. Por su parte, los comunistas mexicanos, como resultado de las divisiones y las expulsiones al interior de su partido, emprendieron la creación de nuevas agrupaciones políticas, coadyuvando de esta manera a conformar el complejo mosaico de la denominada izquierda política mexicana. Sin embargo, considero pertinente advertir que, a pesar de las divi-

${ }^{12}$ Las sedes del Festival Mundial de la Juventud Democrática y los Estudiantes fueron las siguientes: Praga, Checoslovaquia en 1947; Budapest, Hungría en 1949; Berlín, RDA en 1951; Bucarest, Rumanía en 1953; Varsovia, Polonia en 1955; Moscú, URSS en 1957; Viena, Austria en 1959; Helsinki, Finlandia en 1962; el de Argel, Argelia, que se realizaría en 1965, fue suspendido; Sofía, Bulgaria en 1968; Berlín, RDA en 1973; La Habana, Cuba en 1978; Moscú, URSS en 1985, y Pyongyang, RPCH en 1989.

${ }_{13}$ Tras la desestalinización fue llamado Premio Lenin de la Paz, el cual estuvo vigente hasta 1989. World Peace Council (1989). 
siones y subdivisiones que estos y otros aliados del cardenismo experimentaron después de que fue transformado el PRM, su herencia anticlerical, sus apelaciones al socialismo, al comunismo, a la democracia, al nacionalismo -con su postura abiertamente en contra del imperialismo estadunidense-, les permitió definirse más o menos en el mismo bando, tener cierto grado de intercambio y coordinación en algunas actividades debido a su vínculo con organizaciones políticas internacionales alineadas al bloque soviético. Así lo ejemplifica la confluencia de su participación en las diversas actividades de la Federación Mundial de la Juventud Democrática o en las actividades anuales programadas por la UIE. Por ejemplo, esta última programó, en 1954, la Fiesta de los Estudiantes y la Juventud de América Central e Islas del Caribe, que tendría por sede la ciudad de Guatemala a finales de $1954 .{ }^{14}$ En el cartel difundido en México por la CJM, a la que estaba afiliada la FECSM, se muestra el protagonismo de la central estudiantil en las actividades encaminadas a convocar y a organizar la conformación de la delegación mexicana que asistiría a dicha Fiesta $;^{15}$ sin embargo, esta no pudo realizarse debido al golpe de Estado que se ejecutó en contra del gobierno de Juan Jacobo Arbenz. Es oportuno mencionar que estos estudiantes mexicanos, antiimperialistas y amigos de la paz, que militaban en las juventudes comunistas del Partido Popular, del Partido Obrero Campesino Mexicano (Росм) de Valentín Campa, organizaron marchas, mítines, y otros actos simbólicos en los que expresaron sus posturas políticas e ideológicas en temas de orden internacional. Por ejemplo, tras el golpe de Estado al gobierno guatemalteco estuvieron muy activos, como también lo estuvieron los hijos del expresidente Cárdenas y de Francisco J. Mújica: Cuauhtémoc y Janitzio. Con marchas, mítines, publicaciones, protestas ante la embajada estadunidense en México, y otros actos simbólicos como portar un listón azul (color de la bandera guatemalteca), manifestaron su rechazo a la injerencia del gobierno estadunidense en ese país centroamericano. Sin embargo, y como puede apreciarse en la documentación consultada, estas expresiones políticas se apagaron con la renuncia oficial de Arbenz el 27 de junio de

14 Dirección Federal de Seguridad. 11-11-54, L-1. Boletín de la Unión Internacional de Estudiantes. Reunión del Comité Ejecutivo. Viena, 19-21 de enero de 1954; Actividades Internacionales de los Estudiantes en 1954, organizadas, apoyadas y auspiciadas por la UIE, p. 28. AGN, México.

${ }^{15}$ Dirección Federal de Seguridad. 11-11-54, L-1, H- 86. Rinde informe sobre la CJM. México, D. F., a 21 de mayo de 1954. Agente 123, Salomón Clavel Gallardo. Véase en el anexo la propaganda que la cJM difundió en México en ese sentido. AGN, México. 
1954..$^{16}$ Algunos informes contribuyen a recuperar del olvido la actividad de los estudiantes mexicanos en esta coyuntura política. Por ejemplo, en un informe se señala que las Juventudes Socialistas del Pосм acordaron efectuar un mitin con los estudiantes normalistas y politécnicos para respaldar los actos simbólicos de apoyo a Guatemala en la UNAM. De acuerdo con las descripciones de un informe de la Dirección Federal de Seguridad (DFs), el mitin fue encabezado por Cuauhtémoc Cárdenas y Janitzio Mújica; y como un acto simbólico de solidaridad entre Guatemala y México, el embajador guatemalteco entregó la bandera de su país a Cuauhtémoc y este hizo lo mismo con la bandera de México, para después izarlas en el patio de rectoría. ${ }^{17}$ Los informes de la DFs refieren algunas otras experiencias estudiantiles mexicanas involucradas en el conflicto internacional de la guerra fría. Por ejemplo, el episodio protagonizado por estudiantes del politécnico y de las escuelas normales vinculadas a la Confederación de Jóvenes Mexicanos, que exigieron, afuera de la Lotería Nacional, el perdón para los esposos Ethel y Julius Rosemberg, acusados de espionaje por el gobierno estadunidense y condenados a morir en la silla eléctrica, lo que finalmente ocurrió el 19 de junio de 1953, siendo la primera ejecución por espionaje realizada en Estados Unidos. ${ }^{18}$ La CJM convocaba a sus miembros entre ellos los estudiantes organizados en la FECSM- a celebrar el 14 de abril, el día de la solidaridad con los jóvenes que dentro y fuera de España luchan en contra de la dictadura de Francisco Franco. La CJM, con el respaldo de las organizaciones estudiantiles que en ella militaban, también enviaba telegramas al gobierno mexicano solicitándole no entablara relaciones de ningún tipo con el gobierno franquista. ${ }^{19}$ Las organizaciones estudiantiles que militaron en la CJM, entre ellas la FECSM, tuvieron una participación activa en los asuntos de

${ }^{16}$ Dirección Federal de Seguridad. 11-11-54, H- 96. Rinde informe sobre la cjM. México, D. F., a 8 de junio de 1954. Firmado por el agente 123, Salomón Clavel Gallardo; 11-43-54, H-125. Se informa en relación con la manifestación de apoyo a Guatemala. México, D. F., a 2 de julio de 1954. Agn, México.

${ }^{17}$ Dirección Federal de Seguridad. 11-11-54, L-1, H- 269-273. Se informa en relación con el comunismo. México, D. F., a 25 de junio de 1954. Firmado por el director de la DFs, coronel Leandro Castillo Venegas. AGN, México.

${ }^{18}$ Dirección Federal de Seguridad. 63-3-53, L-1, H-370. Informa [sic] Instituto Politécnico Nacional. México, D. F., a 19 de junio de 1953. Firmado por agente 100 Ricardo Ruiz Hidalgo/ agente 129 Héctor Santillán Ortega; 63-3-53, L-1, H-368. Memorándum, se informa en relación con las investigaciones practicadas por esta dependencia en relación al IPN. México, D. F., a 19 de junio de 1953. Firmado por director de la DFS Leandro Castillo Venegas. AGN, México.

${ }^{19}$ Dirección Federal de Seguridad. 11-11-54, H-77. Rinde informe sobre la CJM. México, D. F., a 3 de abril de 1954. Firmado por el agente 123, Salomón Clavel Gallardo. AGN, México. 
orden internacional debido a su militancia en la Federación Mundial de la Juventud Democrática y la Unión Internacional de Estudiantes. En uno de los folletos de difusión que dichas organizaciones emitieron y que la DFs adjuntó a uno de los informes sobre la сјM, se menciona que las actividades de esos organismos internacionales tenían como propósito "facilitar las reuniones entre los estudiantes de diversas naciones y opiniones, a fin de que se conozcan mejor unos a otros y aprendan a respetar los ideales democráticos de los demás, buscando ante todo los intereses y los objetivos que le son comunes". ${ }^{20}$ Mediante diversas actividades académicas, artísticas, recreativas y deportivas como campamentos estudiantiles de verano, juegos mundiales universitarios de verano, el Torneo Internacional Estudiantil de Ajedrez, Reunión de Expertos de la Salud, apoyo para publicaciones o para realizar las fiestas de los estudiantes y la juventud, el Festival Mundial de la Juventud y los Estudiantes, facilitaba la confluencia de jóvenes de diferentes tendencias políticas y religiosas para orientarlos hacia la cooperación internacional y a favor de la paz, la libertad, la democracia, la independencia y la igualdad, lo cual necesariamente implicaba una consciente y persistente lucha contra el macartismo e imperialismo estadunidense. Un estudio sobre el impacto de este tipo de organizaciones internacionales, que centraron su atención en los jóvenes escolarizados de América, África, Asia y Europa, resultaría muy importante para ilustrar la formación política e ideológica de una generación de jóvenes que se movió en los ámbitos de la política, las letras, la danza, la arquitectura, la medicina, y demás ámbitos culturales, con una visión pro soviética y a favor de las democracias populares del mundo comunista. Por ejemplo, Lionel Soto Prieto, quien a los 27 años formó parte del Comité Ejecutivo de la UIE en $1954,{ }^{21}$ tras la revolución cubana participó activamente en el gobierno revolucionario y ocuparía, entre otros cargos, la embajada de Cuba en la Unión Soviética (Cantón y Duarte, 2006). En 1953, la CJM y las organizaciones estudiantiles que en ella militaban, entre ellas la FECSM, promovieron la asistencia al IV Festival Mundial de la Juventud Democrática y los Estudiantes, que fue celebrado en Bucarest, Rumanía, y al que asistió una numerosa delegación mexicana. Como venía ocurriendo, la FECSM envió como su representante a su secretario

${ }^{20}$ Dirección Federal de Seguridad. 11-11-54, L-1. Boletín de la Unión Internacional de Estudiantes. Reunión del Comité Ejecutivo. Viena 19-21 de enero de 1954, p. 14. AGN, México.

${ }^{21}$ Dirección Federal de Seguridad. 11-11-54, L-1. Boletín de la Unión Internacional de Estudiantes. Reunión del Comité Ejecutivo. Viena 19-21 de enero de 1954, p. 30. AGN, México. 
general, quien para entonces era el estudiante normalista Vicente Oria Razo. ${ }^{22}$ La delegación mexicana que asistió a este Festival fue presidida por Guillermo Arriaga Fernández, "danzante del INBA, antiimperialista y amigo de la Paz", y por el vicepresidente de la misma, Amado Tame, del Partido Popular. ${ }^{23}$ Es oportuno mencionar que fue en dicho festival donde Guillermo Arriaga Fernández presentó por primera vez en el extranjero su obra Zapata, que lo posicionaría como el coreógrafo más representativo del nacionalismo mexicano en la danza. ${ }^{24}$ En un informe de la DFS sobre este asunto, se menciona que el pintor Diego Rivera asistiría personalmente y que enviaría por su cuenta a un grupo de diez danzantes indígenas; también que "el comité nacional pro Festival" acordó reunir fondos para financiar su viaje, solicitando ayuda económica "a todas las personalidades tanto sociales como particulares". Sin embargo, "en contra de la opinión de muchos de ellos, la Juventud Comunista pidió que no se solicitara ayuda al gobierno y concretamente al presidente de la república”. El informe también refiere que el comité nacional pro Festival estableció puntualmente los asuntos que le interesaba tratar con el secretario general de la Federación Mundial de la Juventud Democrática. Al respecto, se menciona que propondrían la creación de un plan de acción latinoamericana para "contrarrestar las mentiras propagadas por el imperialismo estadunidense y su gobierno, que hacen de nuestro pueblo y de nuestra juventud lo que quieren"; hablarían acerca de "la necesidad de ayudar y estimular al movimiento juvenil de México" para que se le otorgara la oportunidad de "participar de cerca y con responsabilidad en los trabajos de dirección de la FMJD, ya que pensamos y creemos que a pesar de los errores y debilidades, el movimiento juvenil mexicano puede servir grandemente a un trabajo de la FMJD en todos los países de América Latina". ${ }^{25}$ Entre los integrantes de la delegación mexicana que asistie-

${ }^{22}$ Dirección Federal de Seguridad. 11-11-53, L-1, H-9-12. Rinde informe sobre la CJM. México, D. F., a 7 de julio de 1953. Firmado por el agente 123 Salomón Clavel Gallardo y el agente 12, Augusto Giovenile, H. AgN, México.

${ }_{23}$ Dirección Federal de Seguridad. 11-11-53, L-1, H-9-12. Rinde informe sobre la CJM. México, D. F., a 7 de julio de 1953. Firmado por el agente 123 Salomón Clavel Gallardo y el agente 12, Augusto Giovenile, H. AGN, México.

${ }^{24}$ Guillermo Arriaga Fernández nació el 4 de julio de 1926 y falleció el 3 de enero de 2014; Bautista, "Murió Guillermo Arriaga", Excélsior, 4 de enero de 2014; Vargas, "Fallece el coreógrafo mexicano Guillermo Arriaga Fernández", La Jornada, 3 de enero de 2014; Amador, "Muere Guillermo Arriaga", Proceso, 3 de enero de 2014.

${ }^{25}$ Dirección Federal de Seguridad. 11-11-53, L-1, H-9-12. Rinde informe sobre la CJM. México D. F., a 7 de julio de 1953. Firma el agente 123 Salomón Clavel Gallardo y el agente 12, Augusto Giovenile H. AGN, México. 
ron al IV Festival de la Juventud Mundial y los Estudiantes tuvieron predominancia los dirigentes de la CJM y las organizaciones que en ella militaban, los cuales estaban principalmente vinculados a dos partidos políticos: la Juventud del Partido Popular y de la Juventud del Partido Comunista Mexicano. Sin embargo, es importante señalar que, durante los años cincuenta, la vida de la CJM y de las organizaciones estudiantiles que en ella militaban, estuvieron estrechamente vinculadas a la vida del Partido Popular. No debemos perder de vista que el secretario general del Comité Mexicano pro Festival fue Samuel Ruiz Mora, presidente de la cjм y muy cercano al Partido Popular. De acuerdo con la documentación consultada sobre este asunto, la CJM, que dirigía Ruiz Mora, fue la encargada de convocar y encabezar la reunión en la que fue elegida la delegación mexicana que asistió al IV Festival de la Juventud Mundial y los Estudiantes. Es oportuno mencionar que en el archivo de la DFs existen informes que llevan por título: "se informa en relación con las actividades de los comunistas". Este tipo de informes refieren, por ejemplo, las actividades políticas de Vicente Lombardo Toledano y de Heriberto Jara, este último como presidente del Comité Mexicano Pro Paz. En este tipo de informes se agregan las actividades realizadas por Valentín Campa y su Partido Obrero Campesino Mexicano, las de su periódico Noviembre, así como el surgimiento de las Juventudes Socialistas Mexicanas, que encabezó Valentina Campa y que, a decir de Valentín, sería un grupo de refuerzo del Pocm, "que se integraría con jóvenes de todas las actividades y clases sociales que laboran en pro del socialismo". ${ }^{26}$ Refiero lo anterior porque en este tipo de informes, en los que también se aluden las actividades de los militantes del PCM, la DFs incluyó los movimientos de la CJM y de la FECSM, lo cual es un registro de la confluencia e interacción que existió entre este amplio espectro político de la izquierda mexicana durante la guerra fría.

En el archivo de la DFs existen otras referencias que ilustran la participación de la FECSM en las actividades convocadas por las organizaciones

${ }^{26}$ Dirección Federal de Seguridad. 11-6-53, L-1, H-44-45. Memorándum, se informa el resultado de las investigaciones practicadas por esta dependencia en relación con las actividades de los comunistas. México, D. F., a 8 de julio de 1953. Firmado por el director de la DFs, Leandro Castillo Venegas; L-1, 11-3-53, H-61. Memorándum, se informa el resultado de las investigaciones practicadas por esta dependencia, en relación con las actividades de los comunistas. México, D. F., a 13 de julio de 1953. Firmado por el director de la DFs, Leandro Castillo Venegas; 11-6-53, L-1, H-39 y 40. Memorándum: se informa el resultado de las investigaciones practicadas por esta dependencia en relación con las actividades de los comunistas. México, D. F., a 7 de julio de 1953. Firmado por el director de la DFs, Leandro Castillo Venegas. AGN, México. 
internacionales antiimperialistas que he venido refiriendo. Por ejemplo, de la participación mexicana en la edición del VIII Festival Mundial de la Juventud y los Estudiantes por la Paz y la Amistad, que tuvo lugar en Helsinki, Finlandia, entre el 28 de julio y el 6 de agosto de 1962. La FECSM participó en las actividades para constituir la delegación mexicana que asistiría a dicho encuentro internacional y, como se procedía en estos asuntos, el secretario general de la FECSM, que era entonces el estudiante de la Escuela Normal Rural de Ayotzinapa, Guerrero, Lucio Cabañas Barrientos, formó parte del comité nacional encargado de conformar la delegación que asistiría a ese festival. ${ }^{27}$ Como hemos venido señalando, a través de su militancia en la CJM, la FECSM participó en los festivales que organizaron de manera conjunta la Federación Mundial de la Juventud Democrática y la Unión Internacional de Estudiantes desde 1947. Y lo que venía sucediendo desde entonces era que la CJM y las organizaciones estudiantiles que en ella militaban, participaban en la conformación de la delegación estudiantil que asistía a dichas reuniones representando a México. En el caso de la FECSM, su secretario general automáticamente formaba parte de la delegación que asistía a este tipo de reuniones internacionales, que eran realizadas cada dos años. Así que es muy probable que Lucio Cabañas Barrientos haya asistido al VIII Festival Mundial de la Juventud por la Paz y la Amistad que tuvo lugar en Helsinki, Finlandia. Entre las anécdotas representativas de este festival puede enunciarse que el encargado de enunciar las palabras de despedida a los jóvenes que ahí se congregaron fue Fidel Castro y que el artista español Pablo Picasso obsequió la acuarela Baile de la Juventud para que fuera el emblema de dicho festival. A propósito de la acuarela, L. Grozman, exdirector de la Juventud Comunista Francesa señaló: "el dibujo con lápiz de acuarela de Picasso fue dado a nosotros por nuestro amigo para el octavo Festival Mundial de la Juventud". ${ }^{28}$ Desde 1947, los preparativos para asistir a este tipo de encuentros internacionales de la juventud escolarizada del planeta fue un acontecimiento que congregó, en un mismo sitio y hacia una misma meta, a los estudiantes normalistas y universitarios mexicanos que militaban en las Juventudes del Partido Popular y del Partido Comunista Mexicano, los cuales se reunían para constituir, de México.

${ }^{27}$ Dirección Federal de Seguridad. Fecsm. 11-117-62, L-1, H-2. 23 de marzo de 1962. AGN,

${ }^{28}$ La Espiga Roja, 15 de septiembre de 2013. Recuperado de http://espina-roja.blogspot. com/2013/09/baile-de-la-juventud-de-pablo-picasso.html 
manera unánime, a la delegación que representaría a México en ese tipo de congresos internacionales. Los valores democráticos, antiimperialistas, anticlericales y socialistas que compartían la FECSM y otras agrupaciones estudiantiles vinculadas al PPS y al PCM favorecieron este tipo de confluencias de manera armónica hasta los albores de los años sesenta.

\section{CONCLUSIONES}

El presente artículo sugiere nuevos actores y aproximaciones para el estudio de la guerra fría. Advierte sobre la importancia de comenzar a preguntarnos sobre cómo se vivió ese conflicto internacional en los entornos escolares del sistema normalista rural. Por las referencias documentales aquí expuestas sabemos que la organización estudiantil que representó a esta comunidad escolar durante la guerra fría estuvo vinculada a organismos internacionales abiertamente alineados al bando soviético, a los que entregó una cuota de representación sindical. Debemos también advertir que se trata de una comunidad escolar integrada por adolescentes y jóvenes de escasos recursos que tuvieron una participación al menos nominal en los foros internacionales de la esfera soviética, a los que periódicamente asistieron mediante su militancia en la Confederación de Jóvenes Mexicanos.

La Federación de Estudiantes Campesinos Socialistas de México nació como una iniciativa de organización estudiantil alentada por el magisterio normalista rural que militaba en el Partido Comunista Mexicano. y fue reconocida por las autoridades educativas del gobierno de Lázaro Cárdenas como la representante nacional de los estudiantes de las Escuelas Normales Rurales en julio de 1935, cuando la Secretaría de Educación Pública formalizó esta relación al respaldar y patrocinar su Primer Congreso Nacional; protocolo que se mantendría vigente hasta finalizar la década de 1960. En el marco de las alianzas fraguadas entre el gobierno de Lázaro Cárdenas y los representantes de la Internacional Comunista en México, la FECSM se incorporó al andamiaje corporativo que el presidente Cárdenas congregó en el Partido de la Revolución Mexicana, al unificarse, en 1939, en la Confederación de Jóvenes Mexicanos, que nació reconocida como el sector juvenil de ese partido y en el que estuvieron agremiadas las organizaciones estudiantiles que respaldaron el proyecto educativo socialista. Si bien en la unificación de la CJM-que unificó a la FECSM, así como a algunas organizaciones estudiantiles universi- 
tarias- participaron los comunistas, razón por la cual la FECSM se adhirió a ella, quedó bajo la dirección del líder sindicalista Vicente Lombardo Toledano quien, para entonces, además de secretario general de la Confederación de Trabajadores de México era, por encargo de la Internacional Comunista, el secretario general de la Confederación de Trabajadores de América Latina. Por consiguiente, no era de extrañar que, una vez que estalló el conflicto internacional de la guerra fría, la Federación de Estudiantes Campesinos Socialistas de México tomara partido en el conflicto bipolar al lado de la Unión Soviética.

Para la Unión Soviética, promover la unidad de la juventud del planeta en una idea favorable hacia su gobierno, le abría la posibilidad de que algún día esos jóvenes consiguieran ocupar puestos de importancia en la dirección de sus países y gobernaran con una visión pro soviética. Aquí se advierte un amplio tema de investigación que sería importante emprender para conocer lo que pasó con estos jóvenes que militaron en organizaciones estudiantiles, que asistieron y se involucraron en los congresos internacionales convocados por organismos internacionales que se movieron en el bando de influencia de la Unión Soviética. En lo que respecta a México y al caso que nos ocupa, los representantes de las organizaciones estudiantiles que participaron en los foros internacionales pro soviéticos no llegaron a ocupar cargos de importancia, como, por ejemplo, la presidencia de la república. Durante la guerra fría se posicionó en México una clase política formada en las aulas universitarias, principalmente de la UNAM, la cual, por cierto, en la década de 1930 había sido férrea opositora a la educación socialista. Entre 1945 y hasta 1982, la presidencia de México fue principalmente ocupada por abogados sin estudios de posgrado en el extranjero. En México, ningún egresado de las Escuelas Normales Rurales ocupó la presidencia de la república, aunque en las elecciones de 1964 hubo un intento. Sin embargo, las Escuelas Normales Rurales sí formaron a una clase política; de sus aulas egresaron maestros normalistas que llegaron a convertirse en líderes sindicales del SNTE y los que promovieron su escisión, presidentes municipales, diputados y hasta gobernadores. De sus aulas también egresaron disidentes del Estado corporativo que encabezaron movimientos armados, como también los hubo de las aulas universitarias públicas y privadas.

En los tiempos de la guerra fría, es decir, en los tiempos en el que existieron dos opciones para conducir los destinos de la humanidad: el socialismo o el capitalismo, el PRI se comprometió a trabajar por la "democracia y la justicia social”. Entonces conservaron las alianzas políticas corporativas con 
los obreros, los campesinos y los estudiantes, que habían sido creadas por el gobierno cardenista y los representantes de la Internacional Comunista en México: la Confederación de Trabajadores de México, la Confederación Nacional Campesina y la Confederación de Jóvenes Mexicanos. A través de su militancia en la CJM, la FECSM formó parte de la estructura corporativa con la que los gobiernos del PRI gobernaron este país durante varias décadas del siglo xx. Pero también, a través de su militancia en dicha central estudiantil, los dirigentes estudiantiles de las Escuelas Normales Rurales participaron en los congresos internacionales convocados por la Federación Mundial de la Juventud Democrática y la Unión Internacional de Estudiantes, organismos vinculados al bloque soviético. Los gobiernos priistas no objetaron durante décadas este entramado de alianzas internacionales de las organizaciones estudiantiles mexicanas, después de todo, figuras emblemáticas del nacionalismo revolucionario que militaban en el PRI, como el expresidente Lázaro Cárdenas, tuvieron cierto grado de libertad para posicionarse en el bando de la alternativa que representó la Unión Soviética.

\section{LISTA DE REFERENCIAS}

Arriaga, A. (1962). El movimiento juvenil. México: Instituto Nacional de la Juventud Mexicana.

Cantón, J. y Duarte, M. (2006). Cuba 42 años de la revolución. Cronología histórica 19591989. La Habana: Editorial Ciencias Sociales.

Carr, B. (1996). La izquierda mexicana a través del siglo xx. México: Era.

Civera, A. (2008). La escuela como opción de vida. La formación de maestros normalistas rurales en México, 1921-1945. México: El Colegio Mexiquense.

Civera, A. (2011). ¡Por qué somos estudiantes de segunda!: la organización de los estudiantes campesinos de México, 1932-1941. En S. González Marín y A. M. Sánchez Sáenz (coords.), 154 años de movimientos estudiantiles en Iberoamérica. México: UNAM.

Cuevas, A. (1984) El Partido Comunista Mexicano 1963-1973: ruptura entre las clases medias y el Estado fuerte en México. México: Editorial Línea/Universidad Autónoma de Guerrero/Universidad Autónoma de Zacatecas.

FeCSM [Federación de Estudiantes Campesinos Socialistas de México] (2011-2012). Cuaderno. Autor/Comité de Orientación Política e Ideológica Nacional. 
López Macedonio, M. (2016). Historia de una relación institucional. Los estudiantes normalistas rurales organizados en la Federación de Estudiantes Campesinos Socialistas de México y el Estado mexicano del siglo xx (1935-1969). (Tesis de doctorado inédita). Centro de Estudios Históricos-El Colegio de México, México.

Ortiz Jiménez, M. (1991). La formación de maestros rurales en el Estado de México 19271940. Escuela Normal Rural de Tenería. (Tesis de maestría). Escuela Normal Superior del Estado de México, México.

Ortiz Briano, S. (2012). Entre la nostalgia y la incertidumbre. Movimiento estudiantil en el normalismo rural mexicano. México: Universidad Autónoma de Zacatecas.

Reyna, J. L. (2009). Para entender el Partido Revolucionario Institucional. México: Nostra Ediciones.

Sepúlveda, M. (1976). "La política educativa y las escuelas rurales en la década de los treintas. El caso de las Escuelas Regionales Campesinas en 1936" (Tesis de maestría inédita). Escuela Nacional de Antropología e Historia, México.

Spenser, D. (2007). Unidad a toda costa. La Tercera Internacional en México durante la presidencia de Lázaro Cárdenas. México: Publicaciones de la Casa Chata.

World Peace Council (1989). Peace Courier (No. 4). En World Peace Council Collected Records (CDG-B Finland), Swarthmore College Peace Collection.

Zea, L. (1963). Del liberalismo a la revolución en la educación mexicana. México: Secretaría de Educación Pública.

\section{OTRAS FUENTES}

Archivos

AGN Archivo General de la Nación, México.

AHSEP Archivo Histórico de la Secretaría de Educación Pública, México.

\section{Hemerografía}

La Jornada, México.

Excélsior, México.

Proceso, México. 